\title{
William Marx, Le tombeau d'Edipe. Pour une tragédie sans tragique
}

\section{Pierangela Adinolfi}

\section{(2) OpenEdition}

1 Journals

\section{Edizione digitale}

URL: https://journals.openedition.org/studifrancesi/3261

DOI: 10.4000/studifrancesi.3261

ISSN: 2421-5856

\section{Editore}

Rosenberg \& Sellier

\section{Edizione cartacea}

Data di pubblicazione: 1 juillet 2013

Paginazione: 503-504

ISSN: 0039-2944

\section{Notizia bibliografica digitale}

Pierangela Adinolfi, «William Marx, Le tombeau d'EEdipe. Pour une tragédie sans tragique», Studi Francesi [Online], 170 (LVII | II) | 2013, online dal 30 novembre 2015, consultato il 02 février 2023. URL: http:// journals.openedition.org/studifrancesi/3261 ; DOI: https://doi.org/10.4000/studifrancesi.3261

Questo documento è stato generato automaticamente il 2 février 2023.

\section{(c) $($ ) $\odot \odot$}

Creative Commons - Attribuzione - Non commerciale - Non opere derivate 4.0 Internazionale - CC BYNC-ND 4.0

https://creativecommons.org/licenses/by-nc-nd/4.0/ 


\title{
William Marx, Le tombeau d'CEdipe. Pour une tragédie sans tragique
}

\author{
Pierangela Adinolfi
}

\section{NOTIZIA}

WILliam MARX, Le tombeau d'CEdipe. Pour une tragédie sans tragique, Paris, Les Éditions de Minuit, 2012, pp. 206.

1 Nel presente studio vengono tracciate le linee di un'incomprensione, dell'equivoco sorto nel corso dei secoli fra la tragedia greca ed i lettori moderni. William MARX sottolinea nell'Introduzione «Que nous fait la tragédie grecque?» (pp. 9-13) come tutto ciò che appartiene alla cultura antica abbia modificato la sua natura e come fra la tragedia classica e la cultura moderna si sia interposta l'arte letteraria. I testi antichi sono stati trasformati dal filtro insidioso della letteratura, autonoma, universalistica, separata dal contesto storico originario (tempo, luoghi e dèi), un'arte che nulla ha a che fare con l'Atene del V secolo avanti Cristo. Per condurre la sua indagine, l'autore parte dall'ultima tragedia conosciuta, «le dernier témoin du genre», l'ultima tragedia di Sofocle che risulta essere anche la più recente di tutte le tragedie conservate e non andate perse, Edipo a Colono. In Edipo a Colono, continuazione della storia dell'eroe divenuto re di Tebe e duramente schiacciato dal suo mostruoso passato, la vita di Edipo ha fine in circostanze misteriose ed inspiegabili. Del sovrano resta soltanto la tomba, introvabile ed inaccessibile come per noi è, precisa l'autore, la tragedia greca.

2 Che cosa rivela della tragedia «cette tragédie sans tragique?» Quattro sono gli elementi essenziali oggetto anche dei capitoli dello studio, ciascuno dei quali preceduto da un breve riassunto degli episodi.

3 La tragedia è una storia di luoghi, ai quali è indissolubilmente legata, e senza di essi non è quasi più niente (capitolo $\mathrm{I}$, «Le lieu», pp. 17-43).

4 La tragedia non ha nulla a che vedere con ciò che comunemente s'intende per «tragique». È impossibile avere un'idea generale di ciò che è stata, di ciò che ha 
significato, della visione del mondo che ha espresso, poiché il corpus disponibile è il prodotto di una trasmissione ideologicamente falsata (capitolo II, «L'idée», pp. 47-83).

5 La tragedia era dotata di poteri per noi inconcepibili, come l'influsso benefico e diretto sul corpo degli spettatori, ciò che per Aristotele è la catharsis (capitolo III, «Le corps», pp. 87-121).

6 Per incarnare gli dèi e gli eroi, la tragedia possedeva un'efficacia religiosa il cui equivalente moderno va forse ricercato in chiesa, ma non nel teatro (capitolo IV, «Le Dieu», pp. 125-158).

7 Sofocle, Eschilo o Euripide non hanno scritto per i lettori moderni, nonostante i nostri ripetuti tentativi di leggere nei loro testi messaggi atemporali sull'uomo, sugli dèi, sul destino, sulla legge. La letteratura è la grande divoratrice che fagocita tutti i testi in ordine sparso, separati dal loro contesto, per nutrirsene e farne la propria materia.

8 La Conclusione «De l'inexplicable», (pp. 159-165), le «Notes» (pp. 169-198) e l'Indice dei nomi chiudono il volume. 